Supplement of Earth Syst. Dynam., 12, 763-782, 2021

https://doi.org/10.5194/esd-12-763-2021-supplement

(c) Author(s) 2021. CC BY 4.0 License.

(c) (1)

Supplement of

\title{
Bookkeeping estimates of the net land-use change flux - a sensitivity study with the CMIP6 land-use dataset
}

\section{Kerstin Hartung et al.}

Correspondence to: Kerstin Hartung (kerstin.hartung@ dlr.de)

The copyright of individual parts of the supplement might differ from the article licence. 

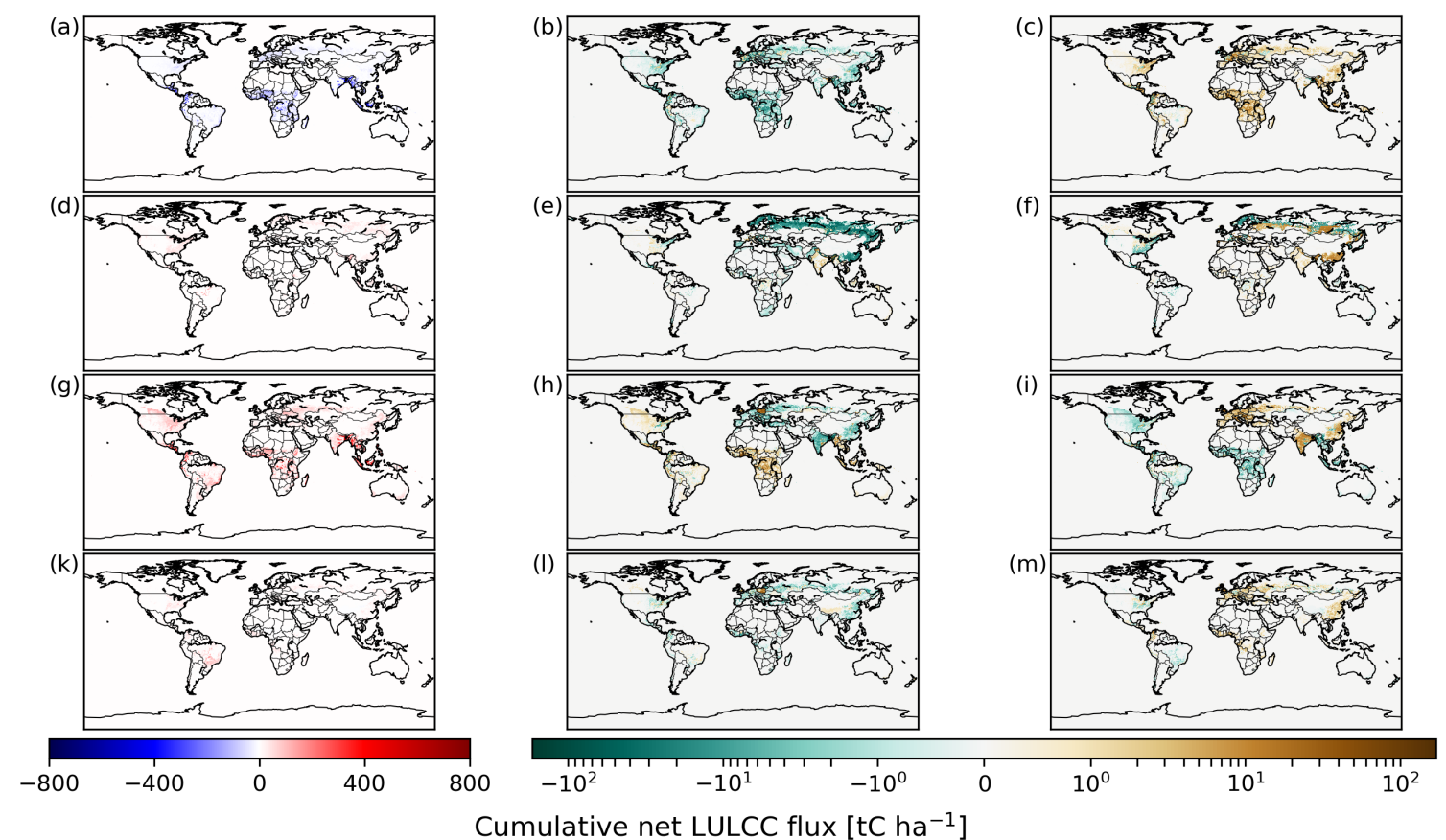

Figure S1. As Fig. 5 but for four LULCC activities abandonment (a-c), harvest (d-f), crop (g-i) and pasture (k-m) in the four rows. LULCC scenarios are aggregated in columns: REG1700 in the first column (a, d, g, k), HI1700-REG1700 in the second column (b, e, h, l) and LO1700-REG1700 in the third column (c, f, i, m). 


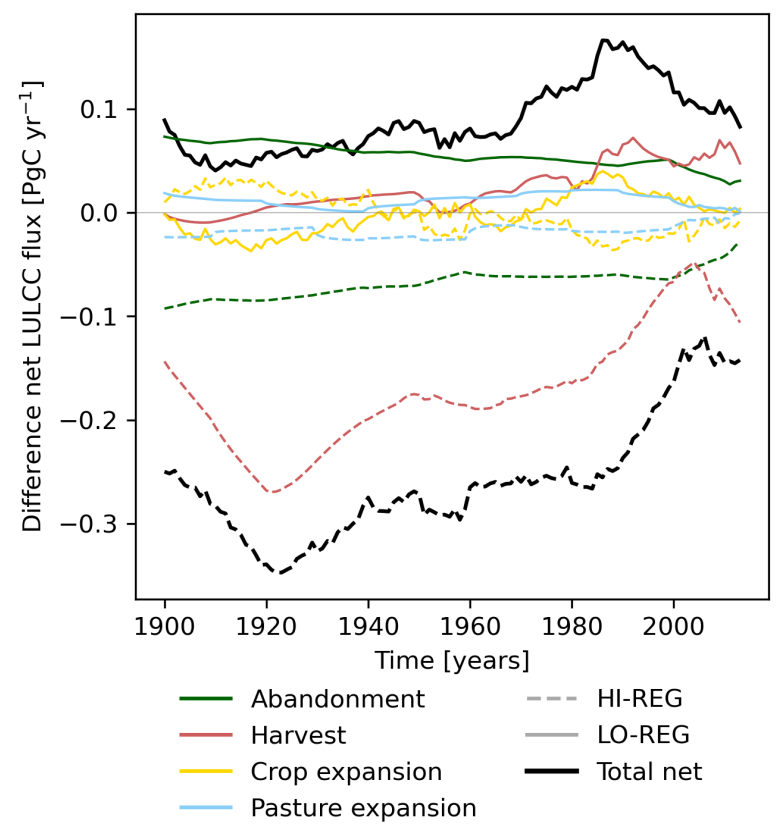

Figure S2. Timeseries of differences of the global annual net LULCC flux for the period 1900-2014 from historical simulations. Shown are the differences HI1700-REG1700 and LO1700REG1700 for the total net LULCC flux and the contribution from each of the four LULCC activities. 

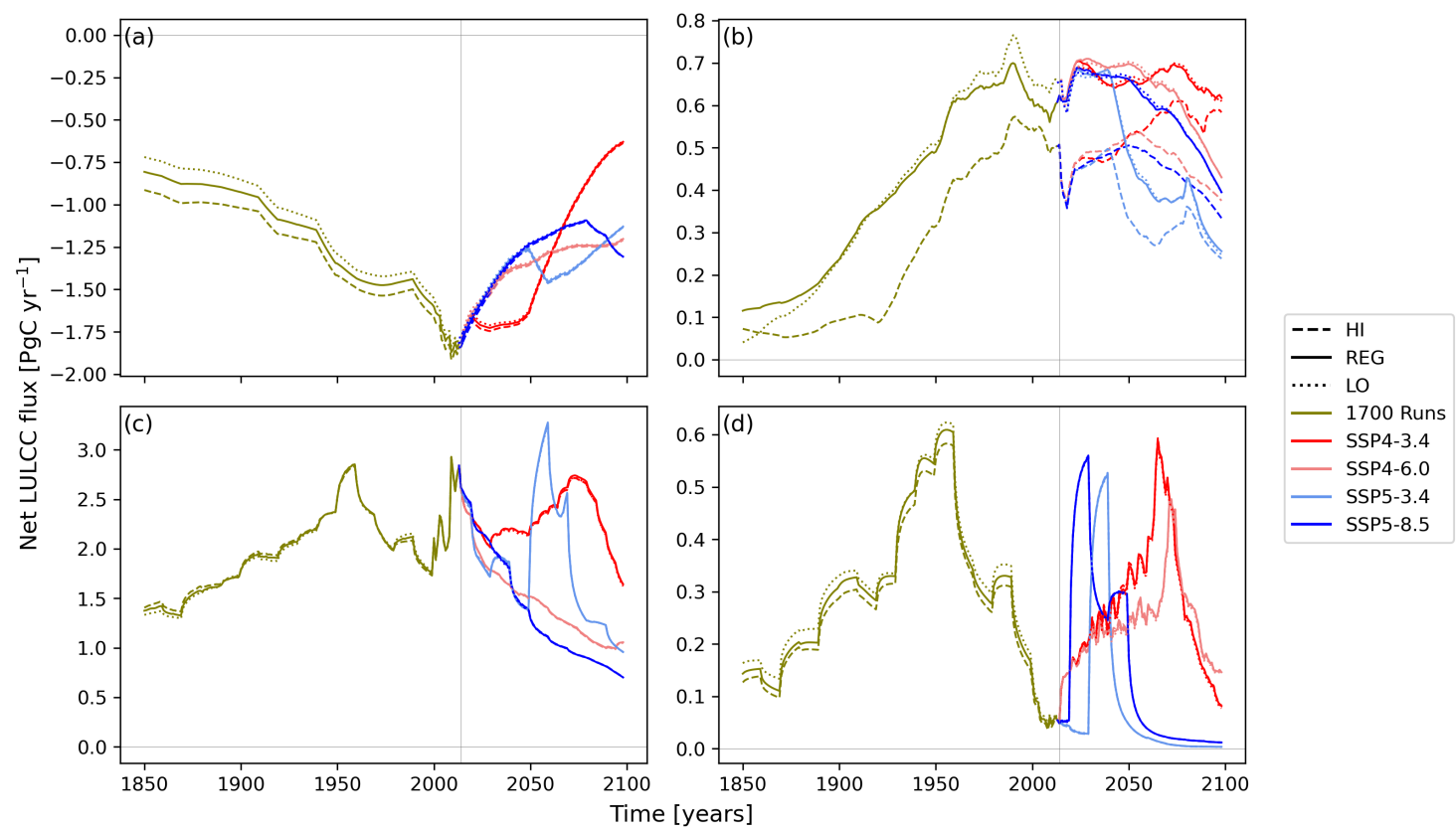

Figure S3. As Fig. 1 but showing global annual net emissions for the four LULCC activities (a) abandonment, (b) harvest, (c) crop expansion and (d) pasture expansion. Note the different $y$-axis ranges. 